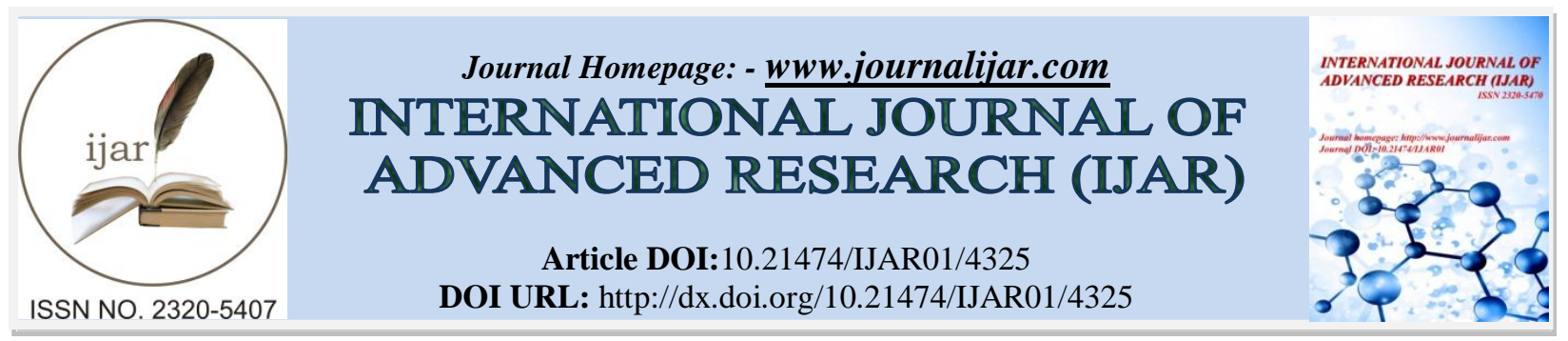

RESEARCH ARTICLE

\title{
ATTITUDE OF ADOLESCENT MOTHERS REGARDING TEENAGE PREGNANCY
}

Mrs. Sonam Tomar ${ }^{1}$, Mrs. Kavitha Mole $\mathbf{P J}^{2}$ and Prof. Dr. N V Munninarayanappa ${ }^{3}$.

1. M.Sc. Nursing Final Year Student, Teerthanker Mahaveer College Of Nursing, Teerthanker Mahaveer University, Moradabad.

2. Professor, Teerthanker Mahaveer College of Nursing, Teerthanker Mahaveer University.

3. Principal, Teerthanker Mahaveer College of Nursing, Teerthanker Mahaveer University.

\section{Manuscript Info}

Manuscript History

Received: 24 March 2017

Final Accepted: 29 April 2017

Published: May 2017

Key words:-

Attitude, perception, experience, teenage pregnancy, adolescent mother

\section{Abstract}

Teenage pregnancy is a pregnancy in women under the age of 20 years and it is a socioeconomic challenge and a public health problem. Every day in developing countries, 20,000 girls under age 18 give birth. This amount to 7.3 million births a year. If that all pregnancies included among them adolescent pregnancy is much higher. Teenage pregnancy rate is high in India that is 62 per 1000 women in the age group of 15-19 years. Statistics show that teenage pregnancy is higher in India other than other countries like in UK 24 per 1000 women and in US were 42 per 1000 women. To explore the attitude of adolescent mothers regarding teenage pregnancy. A qualitative approach was used for the study. Phenomenological design used in this study. The study was conducted in selected Hospital at Moradabad among 10 adolescent mothers in between the age of 18-19 years using convenient sampling technique. In depth interview conducted to collect the data by using semi structured open ended questionnaire to explore the attitude of adolescent mothers regarding teenage pregnancy. Analysis of the data done by content thematic analysis. Adolescent mothers are having the attitude that early pregnancy is a negative event with consequences such as unemployment, limits in education and reduced parental skills. Majority of adolescent mothers were not accepting the early pregnancy and it occurs due to husband and family pressure. A few of adolescent mothers have positive attitude regarding teenage pregnancy. The main conclusion of this study that identified some factors which caused teenage pregnancy such as husband and family pressure, lack of education, cultural constraints and lack of assertiveness. Teenage pregnancy is a public health problems. So some strategies must be build up for preventing teenage pregnancy by increasing the awareness of adolescent mothers regarding contraception methods. These kind of strategies can prevent the teenage pregnancy will also effect on HIV and other sexual transmitted disease. 


\section{Introduction:-}

Adolescence words comes from the Latin verb adolescere which means "to grow up". Adolescence is the time between being a child and full adults this is a period during which a person is physically adult but emotionally immature. In English language are frequently "teenagers" or "teens", which comes from the end of the English words "thirteen to nineteen". (Wikipedia)

Teenage pregnancy is a pregnancy in women under the age of 20 years and it is a socioeconomic challenge and a public health problem. 20,000 girls under the age 18 give birth in developing countries every day. This amounts to 7.3 million births a year. Adolescent pregnancy is much higher than other cases of pregnancy. (Wikipedia).

According to United Nation Statistics Division, India had 86 cases per 1000 women in the age group of 14-19 years in between the years 1995-2010 who have had teenage pregnancy. In India premarital sex is not really trend but cultural restrictions pushed women to have more child even if they don't want child. It leads to illness and weakness. (Amos, 2016)

This is clearly evident that teenage pregnancy is higher in India than United Nation and United Kingdom. The main reason of teenage pregnancy is child marriage, illiteracy, poverty, peer pressure (Vatsal, 2011). Lack of proper sex education in schools, unavailability of reliable contraceptive methods and when poor coitus communication (Kanku. T, 2009). This all leads adolescents to have unprotected sex. In developing countries like India, one of the cause of teenage pregnancy age old customs that support child marriage. (Vatsal, 2011)

Lower age at marriage and lesser gap between marriage and pregnancy may be one of the cause of the high percentage of teenage pregnancies. Legislation is there for the age of marriage for both girls and boys that is 18 years for girls and 21 years for boys but after that also every year many girls get married and become pregnant or give child birth before 20. (Purva, Ravinder, et.al, 2015)

Teenage pregnancy adversely affect the adolescent mothers. It is difficult for adolescent mothers with their baby for adopting new environment. Study shown that most of adolescent mothers dropped out the schools due to their early pregnancy. At the time when she should enjoy life with their friends, she spends her time worrying about how to handle the pregnancy. (Amos, 2016)

The enormous risk factors and complications are there which is due to teenage pregnancy such as barrier to achieve goals in education field, lacks to get prenatal care, gains less weight during pregnancy, premature labour, anaemia, depression, hypertension, preeclampsia during pregnancy and in baby such as low birth weight and premature baby mental retardation and other disabilities. (Amos, 2016). Some study shown that early pregnancy is also risk factor for HIV and Sexual transmitted disease. (Kanku. T, 2009).

\section{Background of the study:-}

Adolescent pregnancy or sometimes termed as "teenage pregnancy" refers to all pregnancies occurring among girls who are below the age of 20 years. Teenage pregnancy is a global problem, sixteen million adolescent girls between 15-19 years old give birth each year which is equal to $11 \%$ of all childbirths worldwide (WHO, 2014).

Teenage pregnancy affect millions of girls every year worldwide. The main focus of this study is to assess the attitude of adolescent mothers regarding teenage pregnancy (Kanku. T, 2009). 32 adolescents give child births for every 1,000 girls aged 15-19 in India ( According to The World Bank, 2013).

Every year 16 million girls aged 15-19 and some 1 million girls under 15 give birth and mostly teenage pregnancy occur in low and middle income countries. Complications during pregnancy and child birth are the second cause of death for 15-19 years old girls globally. The average global birth rate between 15-19 years old is 49 per 1000 girls according to world health statistics in a year (WHO, SEP 2014).

Teenage pregnancy rate is high in India. 62 women out of a total number of 1000 in the age of 15-19 years. Statistics show that teenage pregnancy is higher in India other than other countries like in UK 24 per 1000 women and in US were 42 per 1000 women (According to a United Nations population fund report in 2013). 
According to UNFA report (United Nations population fund report) 11,875,182 teenage pregnancy occur, in which India topped among the 10 countries in between 2000 and 2013. Teenage pregnancy is one of the issues in developed countries such as United States and in developing countries like India. In India, teenage pregnancy is higher than United States. Adolescent girl population is highest in India. UNFA predicted that change will hardly occur from 2010 to 2030. If this trend will keep going like this way, it can be imagined that where India can stand in term of teenage pregnancy after few years. (Taha Amin, 2015)

There is a need to inform the adolescents about using contraception methods and about the benefits of contraceptives and empower them in area to maintain their healthy sexual life. To overcome this problem there is need to conduct further study to evaluate the effect of different interventions for preventing the teenage pregnancy. (Kanku, 2009).

In India major cause of teenage pregnancy is early marriage and lack of education. The statistical report reflects on the number of dying adolescent mothers due to early pregnancy and childbirth. (Himanshi, 2008 )

Teenage pregnancy is a public health problem which needs urgent attention. This is being addressed through the reproductive health programme for adolescents. Most studies reflected that adolescent mothers felt early pregnancy as hard in many aspects. Mass media is a good source of communicating the information which is helpful to increase the awareness about the teenage pregnancy among people and who is teenager and help to prevent the teenage pregnancy in rural areas and urban areas also (Herman, 2008).

There is a need to address the reproductive health programs. They should be organized in schools which is helpful for preventing the teenage pregnancy. Researcher stated that there is need to conduct the further research to explore the incorporation attitude of adolescents for attending the programs and policies which is providing by health care professional worker. Some subsequent studies can be included in the correlation of adolescent's attitudes and belief regarding sexual behaviour. Prevention programs need to focus more on attitude of adolescent mothers regarding teenage pregnancy and such programms will be a motivation to delay sex and use effective contraception in every case. (Herman. 2008)

\section{Statement of the problem:-}

"A qualitative study on attitude of adolescent mothers regarding teenage pregnancy in selected Hospital at Moradabad, UP."

\section{Purpose of the study:-}

This study is a deliberate effort to contribute to a deeper understanding of the issues by attitude of adolescent mother's on the matter and to identify those factors which may influence the risk of pregnancy and suggest possible intervention.

\section{Objective:-}

To explore the attitude of adolescent mothers regarding teenage pregnancy using semi structured questionnaire.

\section{Material and Methods:-}

Research approach:-

Qualitative research approach is a systematic subjective approach used to describe life experiences and giving them meaning. In this study no manipulation has been done. This research approach is helpful to get deep information regarding way of thinking and feelings of adolescent mothers regarding teenage pregnancy.

\section{Research Design:-}

In this study phenomenological research design was used because it helped to generate the way of thinking, feelings and views from the study participants who had experienced of pregnancy as adolescent.

\section{Research Settings:-}

Setting refers to the area where the study was conducted. The study was conducted in selected Hospital at Moradabad, UP. 


\section{Population:-}

Population for the study was postnatal adolescent mothers.

\section{Sample \& sample size:-}

$\checkmark$ Mothers who met the inclusive criteria were selected as sample.

$\checkmark$ Sample size-10

\section{Sample techniques:-}

Convenient sampling technique is followed to select sample. Convenience sample described as easily accessible and meets the inclusive criteria set for the study.

\section{Sample Criteria:- \\ Inclusion criteria:- \\ Adolescent mothers - \\ $\checkmark$ aged between 18-19 years. \\ $\checkmark \quad$ who admitted and delivered baby in selected hospital at Moradabad.}

Exclusion criteria:-

Adolescent mothers-

- who is not interested to participate in study.

- $\quad$ with diagnosed mentally illness.

- who cannot communicate in Hindi or English.

Variables:-

Research variable - Attitude of adolescent mothers regarding teenage pregnancy.

Procedure for data collection:-

- Informed written consent was taken from participants.

- Data collection was done from 03/03/2017 to 18/03/2017.

- Informed written consent was taken from participants.

- The interview started at $9 \mathrm{am}$.

- During interview the interviewer worn casual dress.

- The data were collected from adolescent mothers regarding teenage pregnancy and those who fulfill the criteria made for the study.

- The participants were given full explanation about the nature and purpose of research study.

- They were also informed about the data collection procedure which involved audio recording for getting the information in a separate room.

- They were also assured about confidentiality of interview.

- The data was collected fromtenparticipants by conducting an in depth interview of 20-30 minutes in a separate room attached to ward by using semi-structured open ended questionnaire.

- The interview was started using some leading questions related to attitude of adolescent mothers regarding teenage pregnancy followed by further questions related to response of the participant.

- The data collected during interview was audio recorded with the permission of the participant.

- Data was collected from the participants until the saturation was achieved.

- Through questionnaires the researcher assessed the attitude of adolescent mothers regarding teenage pregnancy.

\section{Result:-}

The audio recorded interview was transcribed to text in Hindi language first and then in English language manually. To check the accuracy of the transcribed data, the recorded interviews were listened again and again. Mistakes too were corrected in this process. Each transcript verbatim was read carefully and read the verbatim several times to creating the themes. The data material was organized manually and analyzed by using coding in thematic content analysis. 
According to Auerbauch \& Silverstein (2003), data analysis had five stages:-

1. Documenting relevant text

2. Identifying repeated data

3. Formulating themes

4. Emergence of theoretical constructs

5. Developing theoretical narratives

\section{Documenting relevant text:-}

The recorded interviews were listened by the interviewer again and again. Researcher, after hearing all the interview recordings were transcribed to Hindi language and then to English language manually.

\section{Identifying repeated data:-}

Identification of relevant data was done from different participants during interview. In this procedure interviewer did the grouping of the entire set of the transcription and the repeated relevant data. Then the repeated data were written separately.

\section{Formulating themes:-}

A key list was formulated on the basis of repeated data such as restrictions in their life, unhappiness with the early pregnancy, facing family members and husband for becoming mother, unwillingness to become pregnant, unhappiness with pregnancy and few mothers were happy.

\section{Emergence of theoretical constructs:-}

Involved organizing group of themes by thorough comparison of each of themes. Those themes were interrelated and combined. The theoretical construct was created in which final theme will be formulated.

\section{Developing theoretical narrative:-}

The previous steps 1-4 were used to bring combination to the entire process of data analysis. In this final step actual quotes from the transcriptions were used to bring to life the participants subjective experiences.

Analysis of the results mainly categorized in themes:-

Table 1:-

\begin{tabular}{|l|l|l|}
\hline S. No & \multicolumn{1}{|c|}{ Themes } & \multicolumn{1}{c|}{ Sub Themes } \\
\hline $\mathbf{1 .}$ & Limits in life & $\begin{array}{l}\mathbf{1 . 1 E d u c a t i o n} \\
\mathbf{1 . 2} \text { Work }\end{array}$ \\
\hline $\mathbf{2 .}$ & $\begin{array}{l}\text { Husband pressure } \\
\text { And family pressure }\end{array}$ & \\
\hline $\mathbf{3 .}$ & Lack of assertiveness & $\begin{array}{l}\text { Acceptance of } \\
\text { pregnancy }\end{array}$ \\
\hline $\mathbf{5 .}$ & Benefit & \\
\hline
\end{tabular}

\section{Limits in life:-}

The adolescent mothers felt some limits in their life because of early pregnancy and delivery. They got restrictions for going out of the house.

\section{Participants said that:-}

$\checkmark \quad$ “......Becoming a mother in early age is very difficult because we cannot live our life freely and free mindedly. Difficulties occur in with new environment......"(P 1).

$\checkmark \quad$ “......During pregnancy and till the delivery of my child my husband and my in-laws didn't allow to me to go outside of the house..... that time Ifelt bad those days...." (P 4)

\section{Sub Themes:-}

\section{Education:-}

Having a child during the adolescent period sets limits to their education. They were unable to continue their education due to family constraints.

Participants said that- 
$\checkmark \quad$ “...I am unable to continue my studies because of my pregnancy and delivery. If I go to school who will take care of my baby...." (P 8).

$\checkmark \quad$ “...It is very difficult to study with child ....because child will create disturbance like crying while I am studying....” (P 9)

\section{Work:-}

The adolescent mothers told that it is difficult to do the work. They also told that they are not getting proper rest because of the baby.

Participant said that-

$\checkmark \quad$ “...... cannot do my work of stitching cloths.... because my baby is small......"(P 8)

$\checkmark \quad$ “.... I cannot do my kite making work with my child....”(P 6).

\section{Husband pressure and family pressure:-}

Some adolescent mothers were not willing to have a child in early age. But because of family and husband pressure they were forced to have the pregnancy.

Participants said that-

$\checkmark \quad$ “..... I told to my husband also that I don't want a child now, but my husband told me that "first baby I want soon"....." (P 1)

$\checkmark \quad$ ".....I was helpless to become a mother in early age because my mother in-law and my sister in-law were pressurizing me for becoming mother and my husband was also doubting me that I am having extra marital affair.... because of all these things to overcome I decided and planned to become a mother and it came to myself respect also....." (P 6)

Acceptance of pregnancy-

Majority of the adolescent mothers were not accepting the pregnancy. They were not happy about being pregnant. Some adolescent mothers were not ready to take care of their baby.

Participants said that:-

$\checkmark \quad$ “...I was not happy with my early pregnancy... Becoming a mother in early age is not good because I am unable to take care of my child properly even my family members and my husband used to tell me that you cannot take care of your child...." (P 10)

$\checkmark \quad$ “......Becoming a mother in early age is very difficult because I don't have knowledge about baby care.........." $(P 3, P 5, P 9)$

\section{Lack of assertiveness-}

Some adolescent mothers were unable to express their feelings in front of their husband and family members because of the lack of assertiveness.

Participants said that:-

$\checkmark \quad$ “.... Because of fear I never said to my husband that I don't want to become mother..... but my husband wants to become a father soon .....” (P 8).

$\checkmark \quad$ “....... I felt so shy.... Because of shyness I didn't tell anything to my husband and my in-laws regarding the pregnancy. ...... Whatever my husband said I agreed for that....”(P 5)

\section{Benefits:-}

Some of the participants were having the attitude that some benefits are there for the early pregnancy that includes more care, love, respect and support from the husband and family members.

Participants said that-

$\checkmark \quad$ “........ am happy with my pregnancy......During the pregnancy and after my delivery my husband and my mother in-laws give more love, care and attention to me than before....." (P 1)

$\checkmark \quad$ “...My family members started to respect me after my delivery...... "(P 6)

\section{Discussion:-}

The result of our study is to focus on attitude of adolescent mothers regarding teenage pregnancy. The findings of study indicated that teenage pregnancy changed their life. Majority of adolescent mothers expressed their feeling and thinking regarding teenage pregnancy that teenage pregnancy is negative event. They said that due to early pregnancy they cannot their life freely and free mindedly. Many restrictions came in their life such as they unable to continue their education and unable to do house hold works with having child which cause future unemployment. 
The first theme of current study shown that adolescent mothers felt some limits in their life because of early pregnancy and delivery. They got restrictions for going out of the house. Majority of participants said that becoming a mother in early age is very difficult because they cannot live their life freely and free mindedly and difficulties occur in adjustment with new environment during pregnancy and till the delivery of child their family didn't allow them to going outside the house, that time they felt very bad. Having a child during the adolescent period sets limits to their education. They were unable to continue their education due to family constraints. Participants said that they were unable to continue their studies because of their pregnancy and delivery. If they think to go to the school who will take care of baby and others said that it is very difficult to study with child because child will create disturbance such as crying while they studying. The adolescent mothers told that it is difficult to do the work. They also told that they are not getting proper rest because of the baby. They cannot do their own work of stitching cloths because of baby.

These current findings correlate with other research finding in which same result found that adolescent mothers didn't get time to take rest when they used to do work and another adolescent mothers said that continue education with having child that is stress. (Herman 2008), (Marya 2012) .

The another main theme of finding show that adolescents become pregnant due to family and husband pressure and their lack of assertiveness. Some adolescent mothers were not willing to have a child in early age. But because of family and husband pressure they were forced to have the pregnancy. Mostly adolescent mother said that they become mother because of family and husband pressure and due to their shyness nature. Some adolescent mother stated that because of fear they never tell to their family about unwillingness to become mother. Some adolescent mothers were unable to express their feelings in front of their husband and family members because of the lack of assertiveness.

The finding of other study(Kanku T 2010, Sunita 2007, S Richter 2014), shown that mostly adolescents got pregnant due to their boy friend pressure and they unable to think to say no for getting pregnant because they fear to lose their relationship.

This is fourth theme in which majority of the adolescent mothers were not accepting the pregnancy. They were not happy about being pregnant. Some adolescent mothers were not ready to take care of their baby. Mostly adolescent mothers said that becoming a mother in early age is very difficult because they don't have knowledge about baby care.

Finding of (S Richter 2014 ) this study showed that teenage mothers were not happy with their teenage pregnancy. In this study teenage mothers reported that this pregnancy was the biggest mistake of their life and they were not ready to takecare of their baby too. They said that they were not ready to have child this was a mistake of their life and they mentioned that teenage pregnancy always create the crisis in their life.

Some of the participants were having the attitude that some benefits are there for the early pregnancy that includes more care, love, respect and support from the husband and family members. Few of participants said that they were happy with their pregnancy.

The finding of (Herman 2008) this study showed that some adolescent mothers were happy with their teenage pregnancy. They said that after having child they closed to their family and improve the negative family environment and to receive love, care, attention and more respect.

\section{Conclusion:-}

Adolescent mothers are having the attitude that that early pregnancy is a negative event with consequences such as unemployment, limits in education and reduces parental skills. From the study it is clearly evident that majority of adolescent mothers were not accepting the early pregnancy and it occurs due to husband and family pressure. A few of adolescent mothers were have positive attitude regarding teenage pregnancy.

\section{Ethical considerations:-}

- Written informed consent was taken from the participants.

- Participants were informed about the study and options were given for discontinuation from study. 


\section{- Implications for nursing}

The current study finding has implication in all field of nursing like nursing practice, nursing education, nursing administration and nursing research . The implications can be discussed as follows:-

\section{Education:-}

- Reproductive health services should be organized in schools and school health nurse should be responsible for guiding these programms to adolescence.

- Nurse should encourage to adolescent mothers for using contraceptive methods.

- Nurse should give counseling to adolescent mothers about continuing education and employment.

\section{Practice:-}

- Comprehensive health services should be available to all adolescents.

- Family planning services for adolescents should be accessible.

\section{Administration:-}

Participants indicated that they think it is necessary to organize the policies, programms in communities and schools for increasing awareness of adolescents to prevent teenage pregnancy.

\section{Research:-}

- The results of this research study may help for further nursing research. Nursing personnel's can conduct the study that will explore the attitude of adolescent mothers regarding teenage pregnancy.

- Further research can be conducted to quantify some factors which uncover in current study to evaluate the effect of different kind of interventions which help to prevent the teenage pregnancy.

\section{Limitations of this study:-}

- The study was a qualitative approach and was based on the individual adolescent mother's attitude regarding teenage pregnancy as well as the sample size of the present study was very small hence generalization cannot be done.

- The study was limited to 18-19 years of adolescent mothers.

- The total participants in this study were ten.

- The study limited to adolescent mothers who become pregnant and delivered the baby.

- The interview was conducted only in one session due to the limitation of the time factor.

- Language has also been an issue because participants were using Arabic language and interview were conducted in Hindi language only according to understanding of participants.

\section{Recommendations:-}

In view of the finding and limitation of the present study. Following recommendations were made based on the findings

1. Avoid the early marriage because somewhere early marriage is the cause of early pregnancy.

2. A quantitative study can be conducted with large sample.

3. A further study can be conducted on other age group also.

\section{References:-}

1. Amos. (2016). Cause and effects of teenage pregnancy. www.indepth-network.org .

2. Auerbauch \& Silverstein. (2003). Qualitative data: An introduction to coding and analysis. NY: NYU Press.

3. Billings.(2007). Teenage parents' experiences of parenthood and views of family support services in Kent. Service user report.

4. Bonnie. (2009). Teen pregnancy prevention programme: Teens attitude towards sexuality.

5. Bowman. (2013). From her perspective: reflections of teenage pregnancy and parenthood. work clinical research papers.

6. Himanshi.(2008).Teen pregnancies higher in India than even UK,US.

7. Edzisani.(2009), "Psychological impact of teenage pregnancy on pregnant teenagers.

8. Judith, Herman. (2008). Adolescent perception of teen births.

9. Julia. (2015). Effect of teenage pregnancy. www.livestrong.com 
10. Kanku.(2010). Attitude, perceptions and understanding amongst teenagers regarding teenage pregnancy, sexuality and contraception in Taung. Division of family medicine and primary care. 52(6), 563-572.

11. King . Teenage Sex: A study of male and female teenagers' attitudes toward teen sex and teen pregnancy.

12. Lebese, Maputle, Chauke, Mabunda. Knowledge and attitudes and perception of students on teenage pregnancy: a case study of rural based university students in South Africa. Department of advance nursing. Department of public health.

13. Maria, Margareta, Louise.(2005). Swedish teenager perceptions of teenage pregnancy, abortion, sexual behaviour and contraceptive habits: a focus group study among 17 years old female high school students. Department of women's and children's health and department of public health and caring sciences.84, 980-986.

14. Mayra. (2012). Parents' perception of teenage pregnancy.

15. Mohar, Liberati. et.al. (2009). The PRISMA group. Preferred Reporting items for systematic Review and Metaanalysis: The PRISMA statement. PLoS Med 6(7): Journal pmed.

16. Nahid. ( 2014).Experience of pregnancy among Iranian adolescent: a qualitative study. Iranian journal of nursing and midwifery research. 19(7), S7-S12.

17. Nimmie.( 2015). A qualitative study exploring the experiences of African Australian teenage mothers in greater Melbourne, Australia.

18. Purva, Ravinder.(2015).Teenage pregnancy: Risk and consequences among adolescent women in rural area in Haryana.

19. Sodi. Egnes. Psychological impact of teenage pregnancy on pregnant teenagers. Thesis and Dissertation(psychology).

20. Spear.(2003).Qualitative research on adolescent pregnancy: A descriptive review and analysis. Journal of paediatric nursing. $18(6)$.

21. Sunita, Walter.(2007). Knowledge and perceptions about sexually transmitted disease: A qualitative study among adolescent students in Uganda. Journal of health population and nutrition. 25(3), 319-327.

22. Taha Amin. (2015). The epidemic of teenage pregnancy: an Indian tragedy. India Tomorrow Journalism of Vision \& Optimism. www.indiatomorrow.net.

23. Teenage pregnancy. https://en.m.wikipedia.org

24. Vatsal.(2011). The triggers of teenage pregnancy in different counteries. Onlymyhealtheditorial team. www.beingtheparent.com .

25. Vo. Pregnant and parenting teens' attitudes toward pregnancy and motherhood and their perceptions of social support. Retrospective Thesis and Dissertations.

26. Wahn. (2007) Teenage childbearing in Sweden. Department of women and child health division of reproductive and Perinatal health care.

27. Watts, Liamputtong, et.al. A qualitative study exploring the experiences of African Australian teenage mothers in greater Melbourne, Australia.

28. World Health Organization.(2014).Adolescent pregnancy. www.who.int 